\title{
Electrochemical methoxymethylation of alcohols - a new, green and safe approach for the preparation of MOM ethers and other acetals $\$$
}

\author{
Xi-Ya Luo, ${ }^{a}$ Xiaofeng Ma, ${ }^{a}$ Frédéric Lebreux, ${ }^{a}$ István E. Markó ${ }^{a}$ and Kevin Lam (D) *b
}

A new, green, safe, cost-effective and highly efficient electrochemical approach for the methoxymethylation of alcohols and phenols was successfully developed. The methodology was also applied to the synthesis of substituted acetals.

The protection of functional groups plays an important role in organic synthesis, especially in the synthesis of complex molecules such as natural products. Among the plethora of protecting groups available to protect hydroxyl groups, methoxymethyl (MOM) ethers have proven to be a popular choice to protect alcohols and phenols due to their high tolerance toward a wide range of reaction conditions. ${ }^{1-4}$ Besides their protective group usage, methoxymethyl ethers are also formal synthons equivalent to formaldehyde that could be used to promote further transformations. Methoxymethyl ethers are usually prepared by reacting an alcohol, or a phenol, with an excess of chloromethyl methyl ether (MOMCl) under basic conditions. ${ }^{5-7}$ Even though this approach leads to the formation of the desired MOM ether in high yields, the extremely high carcinogenicity of $\mathrm{MOMCl}$ is a major drawback which makes this approach hazardous and unpractical, especially on a larger scale. ${ }^{8}$ In order to circumvent the toxicity of $\mathrm{MOMCl}$, formaldehyde dimethyl acetal has been introduced as a surrogate. ${ }^{9-14}$ However, there are some disadvantages associated with the use of this new reagent due to its inherent low reactivity. Lewis acids and harsher conditions using high temperatures and longer reaction times have now to be used. Tedious workup and purification procedures are also very often required. Alternatively, methoxymethyl-2-pyridylsulfide (MOM-ON) has been introduced as a new reagent for the

\footnotetext{
${ }^{a}$ Université Catholique de Louvain, Laboratory of Organic and Medicinal Chemistry, Bâtiment Lavoisier, Place Louis Pasteur 1 bte L4.01.02., B-1348 Louvain-la-Neuve, Belgium

${ }^{b}$ Department of Pharmaceutical, Chemical and Environmental Sciences, Faculty of Engineering and Science, University of Greenwich, Central Avenue, Chatham Maritime, ME4 4TB, UK. E-mail:k.lam@greenwich.ac.uk

$\dagger$ Dedicated to the memory of Professor István E. Markó.

\$ Electronic supplementary information (ESI) available. See DOI: 10.1039/c8cc05843a $\S$ Deceased on the 31st of July 2017.
}

methoxymethyl etherification of alcohols and phenols. $^{15}$ Although it circumvents some of the previous issues, there is still an urgent need for greener and safer alternatives to $\mathrm{MOMCl}$.

Synthetic organic electrochemistry takes its roots from Faraday's ${ }^{16}$ and Kolbe's ${ }^{17}$ classic works on electrolysis of aliphatic carboxylic acids. Although numerous transformations have been developed ever since ${ }^{18-23}$ and many of them have been successfully used in several industrial processes, ${ }^{22,24}$ the potential of preparative organic electrochemistry remains underestimated even though electrosynthesis represents one of the safest and greenest methods to perform organic redox reactions. Hopefully, the new commercially available Electrasyn 2.0 electrolysis setup will facilitate the use of electrosynthesis in organic synthetic laboratories. ${ }^{25}$ Herein, we would like to disclose a new efficient and environmentally benign anodic methodology for the methoxymethylation of alcohols and phenols relying on the Hofer-Moest decarboxylation of $\alpha$-alkoxy carboxylic acid derivatives (Scheme 1). ${ }^{26-29}$

A series of $\alpha$-alkoxy carboxylic acids were prepared in excellent yields, by treating the corresponding alkoxide with a bromoacetic acid derivative (Table 1). ${ }^{30}$

The preparation of the $\alpha$-alkoxy carboxylic acids 3 follows a simple and robust procedure that could be performed at a gram-scale level without showing any significant decrease in yields. As seen from Table 1, a wide variety of alcohols, including phenol, were converted into their corresponding $\alpha$-alkoxy

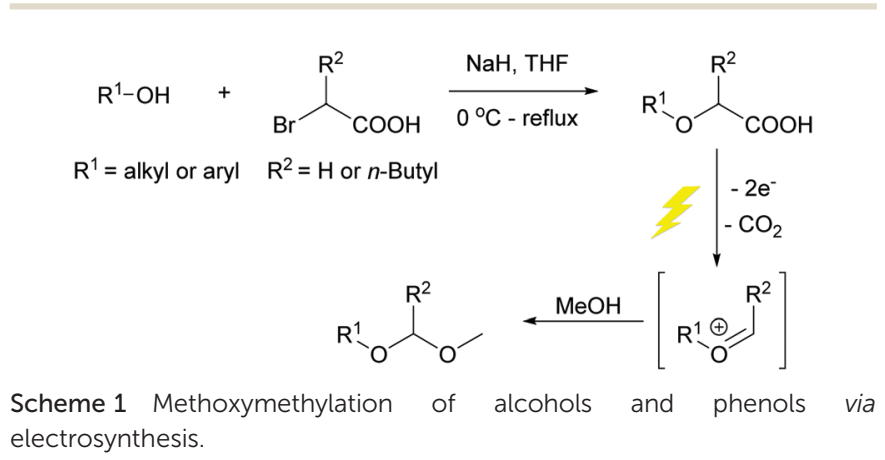


Table 1 Synthesis of $\alpha$-alkoxy carboxylic acids ${ }^{a}$

1
$\mathrm{R}^{1}=$ alkyl or aryl
$\mathrm{R}^{2}=\mathrm{H}$ or $n$-Butyl

Entry Alcohol $1 \quad$ Carboxylic acid $3 \quad$ Yield $^{b}(\%)$
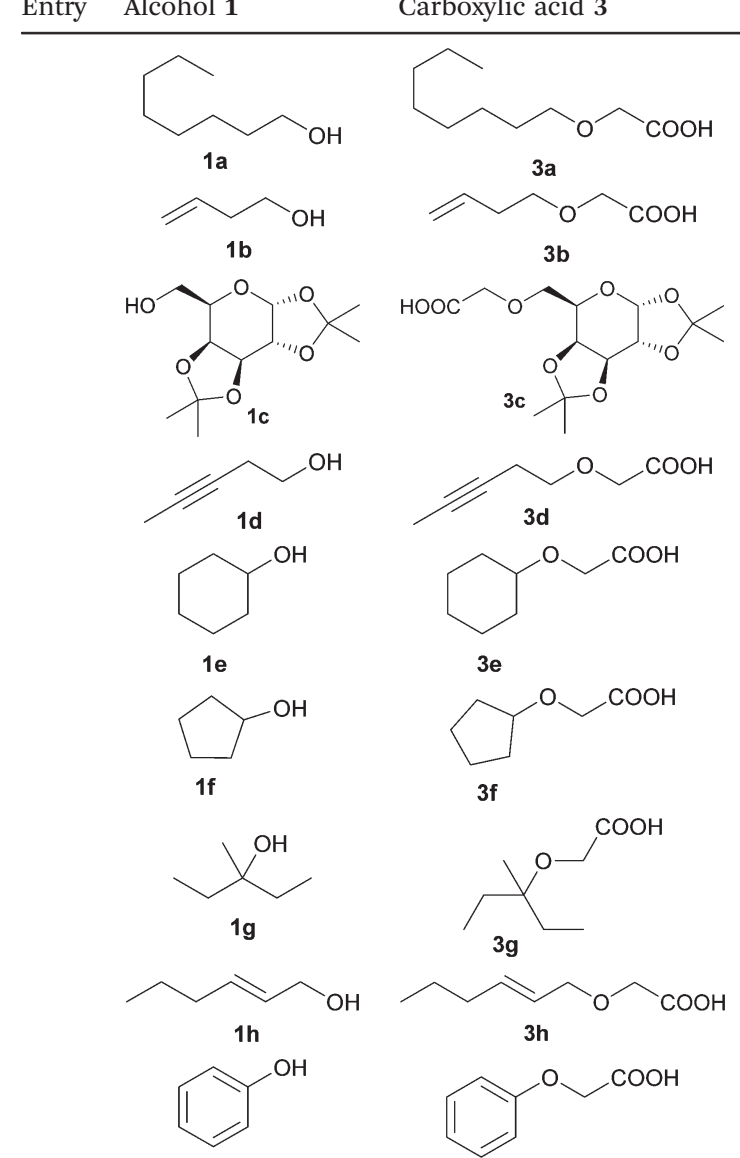

$1 \mathrm{i}$<smiles>C=C(C)CCO</smiles>

$1 \mathrm{j}$

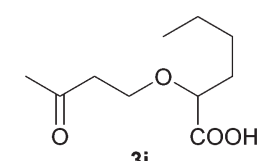

$3 \mathbf{j}$

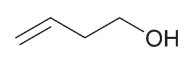

$1 \mathrm{k}$

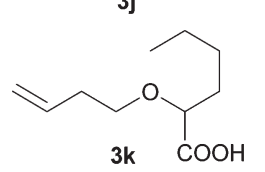

${ }^{a}$ The reaction was conducted with $10 \mathrm{mmol}$ of alcohol 1. ${ }^{b}$ Yield of pure and isolated 2. ${ }^{c}$ 2-Bromohexanoic acid was used. ${ }^{d}$ Yield over two steps (etherification and ozonolysis).

carboxylic acid derivatives. Only alcohols bearing a ketone moiety are shown to be problematic due to the inherent acidity of the hydrogen atoms in the $\alpha$ position to the carbonyl position. A way to circumvent this limitation was to use an alkene, as a surrogate for the ketone, such as $\mathbf{1} \mathbf{j}$, and to submit its $\alpha$-alkoxy carboxylic acid derivative to ozonolysis conditions in order to generate the desired ketone (Table 1, entry 10, see the ESI $)$.
The impact of several electrolysis parameters on the fate of the electrochemical reaction was then investigated and salient results are summarised in Table 2. To perform the anodic decarboxylation, carbon graphite was chosen as the electrode material since this specific type of carbon is known to adsorb organic molecules, and therefore promotes multielectron transfers. ${ }^{31,32}$ The electrochemical oxidation of compound $\mathbf{3 a}$ was carried out in an undivided cell equipped with two $6 \mathrm{~cm}^{2}$ graphite electrodes, spaced $5 \mathrm{~mm}$ apart, at room temperature. The addition of a catalytic amount of base at the initial stage of the electrolysis generates a small amount of carboxylates that provides the necessary conductivity to the medium. ${ }^{33}$ Since the reaction is carried out in an undivided cell, methoxide ions are continuously formed at the cathode at the same rate as the carboxylate ions are consumed at the anode during the electrolysis. When submitted to these electrolytic conditions, carboxylic acid 3a was converted into its corresponding MOM ether 4a. Much to our surprise, neither the current density (entries 1, 7 and 8) nor the nature of the base (entries 1 and 6) is shown to have an impact on the fate of the reaction. As expected, the use of a homemade electrolysis setup or Electrasyn 2.0 led to the same results (entries 7 and 8). However, the presence of methanol is shown to be critical. Decreasing the amount of methanol led not only to lower yields and but also to longer reactions times (entries 2 to 5).

With the optimal conditions in hands (Table 2, entry 1), the scope and limitations of the methodology were explored by anodically oxidising the previously prepared $\alpha$-alkoxy carboxylic acid derivatives. The results are summarised in Table $3 .{ }^{34}$ In each case, the desired MOM ether was obtained in a good to excellent yield (75-93\%) without the need to perform any purification other than a simple workup. Steric hindrance does not seem to have an impact on the reaction since primary (entries 1-4), secondary (entries 5 and 6) and tertiary (entry 7) derivatives are all giving high yields of the desired adduct 4 .

Table 2 Influence of the electrolysis parameters ${ }^{a}$

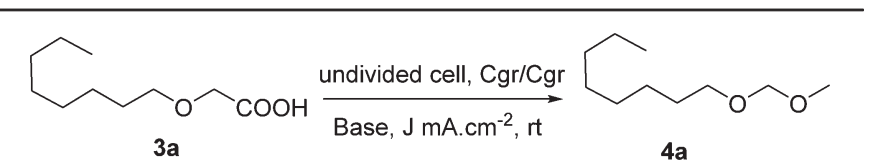

\begin{tabular}{|c|c|c|c|c|c|c|}
\hline \multirow[b]{2}{*}{ Entry } & \multicolumn{2}{|c|}{ Solvent (\%) } & \multirow[b]{2}{*}{ Base } & \multirow[b]{2}{*}{$J\left(\mathrm{~mA} \mathrm{~cm}^{-2}\right)$} & \multirow{2}{*}{$\begin{array}{l}\text { Chemical } \\
\text { yield }^{b}(\%)\end{array}$} & \multirow{2}{*}{$\begin{array}{l}\text { Faradic } \\
\text { yield (\%) }\end{array}$} \\
\hline & $\mathrm{MeOH}$ & $\mathrm{THF}$ & & & & \\
\hline 1 & 100 & 0 & NaOMe & 100 & 90 & 0.15 \\
\hline 2 & 50 & 50 & NaOMe & 100 & 87 & 0.15 \\
\hline 3 & 25 & 75 & NaOMe & 100 & 71 & 0.15 \\
\hline 4 & 10 & 90 & $\mathrm{NaOMe}$ & 100 & 60 & 0.06 \\
\hline 5 & 5 eq. & $\sim 100$ & $\mathrm{NaOMe}$ & 100 & Degradation & 0.01 \\
\hline 6 & 100 & 0 & $\mathrm{KOH}$ & 100 & 90 & 0.10 \\
\hline 7 & 100 & 0 & $\mathrm{NaOMe}$ & 50 & 90 & 0.15 \\
\hline $8^{c}$ & 100 & 0 & $\mathrm{NaOMe}$ & 50 & 90 & 0.15 \\
\hline
\end{tabular}

${ }^{a}$ Reaction conditions: 2-(octyloxy)acetic acid 3a (1.87 mmol), solvent $(50 \mathrm{~mL})$, base $(0.46 \mathrm{mmol})$; graphite electrodes $(2 \mathrm{~cm} \times 3 \mathrm{~cm})$; the electrolysis was conducted at constant current until the total consumption of the starting material was reached. ${ }^{b}$ Quantified by GC. ${ }^{c}$ Performed using Electrasyn 2.0. 
Table 3 Electrooxidation of $\alpha$-alkoxy carboxylic acids ${ }^{a}$

$\mathrm{R}^{1}=$ alkyl or aryl
$\mathrm{R}^{2}=\mathrm{H}$ or $n$-Butyl

\begin{tabular}{|c|c|c|c|}
\hline Entry & $\alpha$-Alkoxy carboxylic acid & MOM ether & Yield $^{b}(\%)$ \\
\hline
\end{tabular}
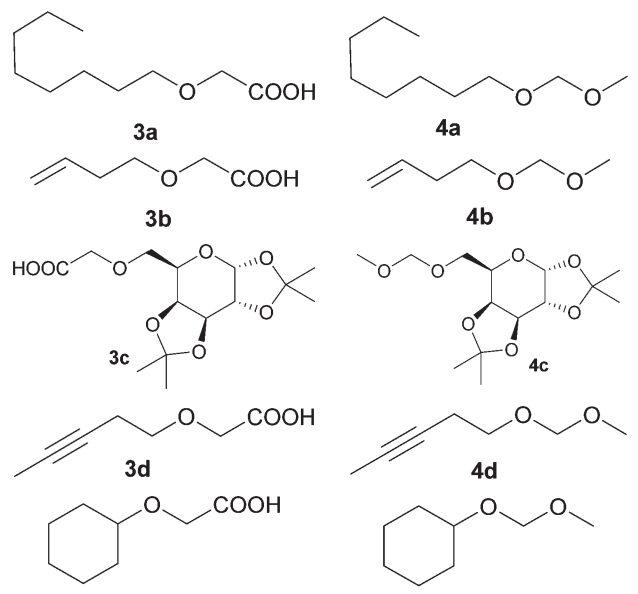

$3 e$

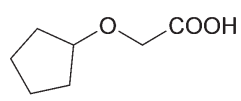

$3 f$

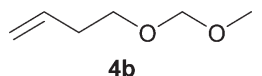

4b
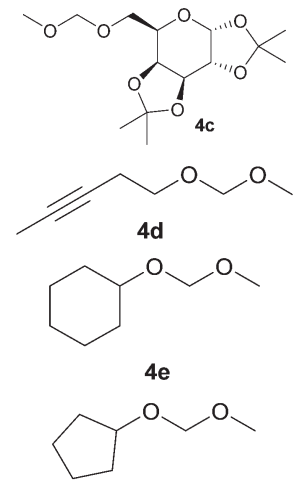

$4 f$

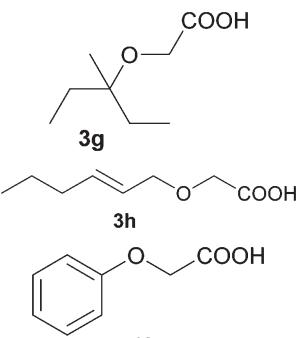

$3 i$
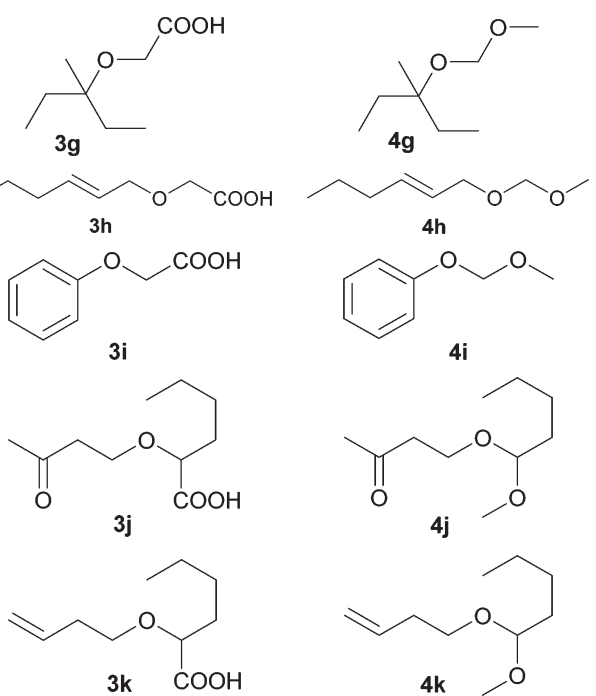

$4 \mathrm{i}$

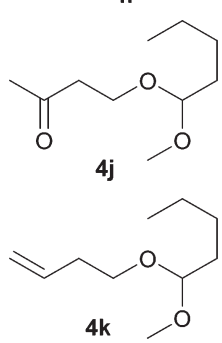

${ }^{a}$ Electrolysis was conducted with $1.87 \mathrm{mmol}$ of 3 in $50 \mathrm{~mL}$ of methanol at r.t. for 70 minutes. ${ }^{b}$ Yield of pure and isolated $4 .^{c}$ The reaction was performed with $5 \mathrm{~g}$ of $3 \mathbf{i}$.

The electrolysis conditions are compatible with a variety of functional groups such as allyls (entry 8), aromatics (entry 9) alkenes (entries 2, 8 and 11), alkynes (entry 4), carbonyls (entry 10) and acetals (entry 3). Moreover, when the reaction was performed with $5 \mathrm{~g}$ of $\mathbf{3 i}$, no decrease in the yield was observed. Only the electrolysis of $\mathbf{3 b}$ led to a lower yield (entry 2) presumably due to the high volatility of $\mathbf{4 b}$. The same

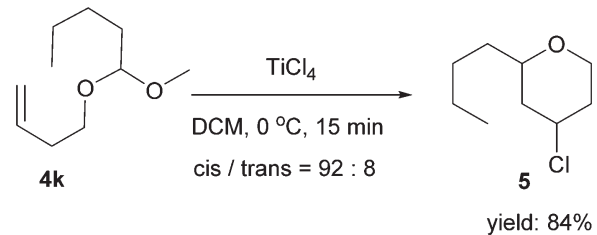

Scheme 2 Synthesis of tetrahydro-2H-pyran from acetals.

methodology was also successfully applied to the synthesis of substituted acetals (entries 10 and 11).

As mentioned earlier, besides being a protecting group, the MOM group could be used as an oxonium precursor. ${ }^{35,36}$ As a proof of concept, the electrochemically prepared $4 \mathbf{k}$ was easily transformed into the tetrahydropyran $\mathbf{5}$, in the presence of $\mathrm{TiCl}_{4}$. The synthesis of such tetrahydropyranic fragments is particularly relevant since this motif is found in numerous natural products and biologically relevant molecules (Scheme 2). ${ }^{12}$

In conclusion, using a homemade electrolysis setup or the commercially available Electrasyn 2.0, we have developed a new, environmentally friendly, safe and cost-effective electrochemical methoxymethylation methodology that does not rely on the use of the carcinogenic MOMCl. The desired MOM ethers were obtained in high yields without requiring any purification, and the same result was observed, even when the reaction was carried out at a gram-scale level. The same methodology has also been used successfully for the synthesis of substituted acetals that could be used as building blocks in the synthesis of bioactive products. Ongoing efforts are now directed toward the transfer of this methodology to flow-cell electrochemistry.

Financial support for this work from UCLouvain, the University of Greenwich and equipment from IKA is gratefully acknowledged.

\section{Conflicts of interest}

The authors confirm the absence of conflicts of interest.

\section{Notes and references}

1 P. J. Kocienski, Protecting groups, Georg Thieme Verlag, Stuttgart. New York, 2005.

2 P. G. M. Wuts, Greene's Protective Groups in Organic Synthesis, John Wiley \& Sons, Ltd, Hoboken, NJ, 5th edn, 2014.

3 G. Sartori, R. Ballini, F. Bigi, G. Bosica, R. Maggi and P. Righi, Chem. Rev., 2004, 104, 199-250.

4 J. P. Yardley and H. Fletcher, Synthesis, 1976, 244.

5 A. F. Kluge, K. G. Untch and J. H. Fried, J. Am. Chem. Soc., 1972, 94, 7827-7832.

6 B. C. Ranu, A. Majee and A. R. Das, Synth. Commun., 1995, 25, 363-367.

7 P. Kumar, S. V. N. Raju, R. S. Reddy and B. Pandey, Tetrahedron Lett., 1994, 35, 1289-1290.

8 R. T. Drew, S. Laskin, M. Kuschner and N. Nelson, Arch. Environ. Health, 1975, 30, 61-69.

9 K. Fuji, S. Nakano and E. Fujita, Synthesis, 1975, 276-277.

10 G. A. Olah, A. Husain, B. G. Balaram Gupta and S. C. Narang, Synthesis, 1981, 471-472.

11 H. K. Patney, Synlett, 1992, 567-568.

12 T. S. Jin, T. S. Li and Y. T. Gao, Synth. Commun., 1998, 28, 837-841.

13 B. Karimi and L. Ma'mani, Tetrahedron Lett., 2003, 44, 6051-6053. 
14 M. Moghadam, S. Tangestaninejad, V. Mirkhani, I. MohammadpoorBaltork, M. Khajehzadeh, F. Kosari and M. Araghi, Polyhedron, 2010, 29, 238-243.

15 B. F. Marcune, S. Karady, U. H. Dolling and T. J. Novak, J. Org. Chem., 1999, 64, 2446-2449.

16 M. Faraday, Philos. Trans. R. Soc. London, 1832, 122, 125-162.

17 H. Kolbe, Justus Liebigs Ann. Chem., 1849, 69, 257-294.

18 D. Hayrapetyan, V. Shkepu, O. T. Seilkhanov, Z. Zhanabil and K. Lam, Chem. Commun., 2017, 53, 8451-8454.

19 K. Lam and W. E. Geiger, J. Org. Chem., 2013, 78, 8020-8027.

20 K. Lam and I. E. Markó, Chem. Commun., 2009, 95-97.

21 E. J. Horn, B. R. Rosen and P. S. Baran, ACS Cent. Sci., 2016, 2, 302-308.

22 Organic Electrochemistry: Revised and Expanded, ed. O. Hammerich and B. Speiser, CRC Press, 5th edn, 2015.

23 X. Ma, X. Luo, S. Dochain, C. Mathot and I. E. Markò, Org. Lett., 2015, 17, 4690-4693.

24 E. J. Horn, B. R. Rosen, Y. Chen, J. Tang, K. Chen, M. D. Eastgate and P. S. Baran, Nature, 2016, 533, 77-81.

25 ElectraSyn 2.0 Package - IKA, https://www.ika.com/laboratoryequipment/products/electrochemistry-kit/products/4265/electrasyn2.0-package, accessed 19 March 2018.

26 H. Hofer and M. Moest, Justus Liebigs Ann. Chem., 1902, 323, 284-323.

27 F. Lebreux, F. Buzzo and I. E. Marko, ECS Trans., 2008, 13, 1-10.

28 F. Lebreux, F. Buzzo and I. Markó, Synlett, 2008, 2815-2820.

29 P. G. M. Wuts and C. Sutherland, Tetrahedron Lett., 1982, 23, 3987-3990.

30 Procedure: A flame dried $250 \mathrm{~mL}$ three-necked flask was equipped with a magnetic stir bar and a reflux condenser. Sodium hydride $(1.20 \mathrm{~g}, 60 \%$ dispersion in mineral oil, $30 \mathrm{mmol})$ was then suspended in dry THF $(20 \mathrm{~mL})$ at $0{ }^{\circ} \mathrm{C}$ under argon. Alcohol $1(10 \mathrm{mmol})$, dissolved in dry THF (30 mL), was then added slowly. After $30 \mathrm{~min}$, bromoacetic acid 2 (10 mmol), dissolved in dry THF $(30 \mathrm{~mL})$, was added dropwise. The mixture was heated to reflux, and the progress of the reaction was monitored by TLC. Upon completion of the reaction, as shown by TLC, the mixture was cooled down to room temperature and diluted with water $(60 \mathrm{~mL})$. The mixture was extracted with hexane $(2 \times 30 \mathrm{~mL})$, the aqueous layer was acidified with $\mathrm{HCl}(2 \mathrm{M})$ until $\mathrm{pH} 2$ was reached and extracted with diethyl ether $(3 \times 30 \mathrm{~mL})$. The combined organic layers were dried over $\mathrm{MgSO}_{4}$, the solvent was removed under reduced pressure and the crude mixture was purified by column chromatography on silica gel (petroleum ether/ethyl acetate) to give the pure $\alpha$-alkoxy carboxylic acids 3.

31 H. Horikawa, T. Iwasaki, K. Matsumoto and M. Miyoshi, J. Org. Chem., 1978, 43, 335-337.

32 H. G. Thomas and E. Katzer, Tetrahedron Lett., 1974, 15, 887-888.

33 H. Tanaka, M. Kuroboshi and S. Torii, in Organic Electrochemistry, CRC Press, 5th edn, 2015, pp. 1267-1307.

34 General Electrolysis Procedure: In an undivided beaker-type cell $(100 \mathrm{~mL})$ equipped with two graphite electrodes $(2 \mathrm{~cm} \times 3 \mathrm{~cm})$, or in an Electrasyn 2.0, $\alpha$-alkoxy carboxylic acid $3(1.87 \mathrm{mmol})$ was dissolved in $\mathrm{MeOH}(50 \mathrm{~mL})$. The acid was then partially neutralised with $\mathrm{NaOMe}(0.46 \mathrm{mmol})$ and a current density of $100 \mathrm{~mA} \mathrm{~cm}^{-2}$ was applied. The reaction was monitored by TLC. Upon completion of the reaction, as shown by TLC, the solvent was carefully removed under reduced pressure and then water $(10 \mathrm{~mL})$ was added (in the cases where the solution was not basic, $5 \mathrm{~mL}$ of $1 \mathrm{M} \mathrm{KOH}$ were added). The aqueous mixture was then extracted with diethylether (3 $\times 15 \mathrm{~mL}$ ). The organic layers were collected, dried over $\mathrm{Na}_{2} \mathrm{CO}_{3}$, and concentrated under reduced pressure to yield the clean product 4 without the need for any further purifications.

35 F. P. Marmsäter and F. G. West, J. Am. Chem. Soc., 2001, 123, $5144-5145$.

36 M. Braun and W. Kotter, Angew. Chem., Int. Ed., 2004, 43, 514-517. 